\title{
POST-OPERATIVE BLOOD PRESSURES IN COARCTATION OF THE AORTA*
}

\author{
BY \\ LAXIMIKANT RATHI AND JOHN D. KEITH \\ From the Department of Pediatrics, University of Toronto, and the Research Institute of the Hospital for Sick Children \\ Toronto, Canada
}

Received November 18, 1963

Gross and Hufnagel (1945) and Crafoord and Nylin (1945) independently reported successful repair of the coarctation of aorta. Since then many thousand patients have had surgical correction of this anomaly (Bailey, 1957; Campbell and Baylis, 1956; Cleland et al., 1956; Keith, Rowe, and Vlad, 1958). There have been numerous reports dealing with the immediate post-operative period (d'Abreau and Parsons, 1956) but very few long-term follow-up studies have been carried out either in children or in the older age-groups.

This report deals with the follow-up results of the patients operated upon for coarctation of aorta, from birth to 15 years of age, at the Hospital for Sick Children, Toronto.

\section{SUBJECTS}

Records of 150 patients operated upon for coarctation of aorta at the Hospital for Sick Children during the past 15 years were reviewed. The cases were divided into two groups. In infant Group A, 27 were operated on during the first year of life, and in child Group B, 123 patients were operated on between 1 and 15 years of age. Patients in Group A were followed from 6 months to 11 years with a mean follow-up of 5.1 years. Of the 123 patients in Group B, 32 were followed from 6 months to 11 years with a mean follow-up of 4.4 years. Blood pressures in the right arm and one of the lower extremities were measured by the conventional blood-pressure cuff and checked by an oscillometer when necessary in infancy (Keith et al., 1958). Of the infants in Group A, 24 per cent and of the children in Group B, 26 per cent had some associated cardiac defect. Patent ductus arteriosus was the most common anomaly found in conjunction with coarctation, The other anomalies included ventricular septal defect, atrial septal defect, aortic stenosis, aortic regurgitation endocardial fibro-elastosis, and mitral regurgitation (Glass, Mustard, and Keith, 1960).

\section{RESULTS}

Group A Infants. Of these infants, 82 per cent had arm pressures well above the normal limits before operation while the others had arm pressures at the upper limits of normal range. In all the pressure was higher in the arm than in the leg. At the last examination, at varying intervals after surgical correction, 67 per cent had normal pressures in the right arm, while 33 per cent still had readings that were slightly or moderately above the normal limits for the age (Fig. 1). Of these patients, 44 per cent had higher residual systolic pressures in the legs, 26 per cent had equal pressures in the arms and legs, and 30 per cent had higher pressure in the arms. In the latter group only 3 of the 7 patients had systolic pressures in the arms over $120 \mathrm{~mm}$. $\mathrm{Hg}$, and 2 of these had associated

* This work was aided by a grant from the Ontario Heart Foundation and the National Health Grants, Ottawa. 671 


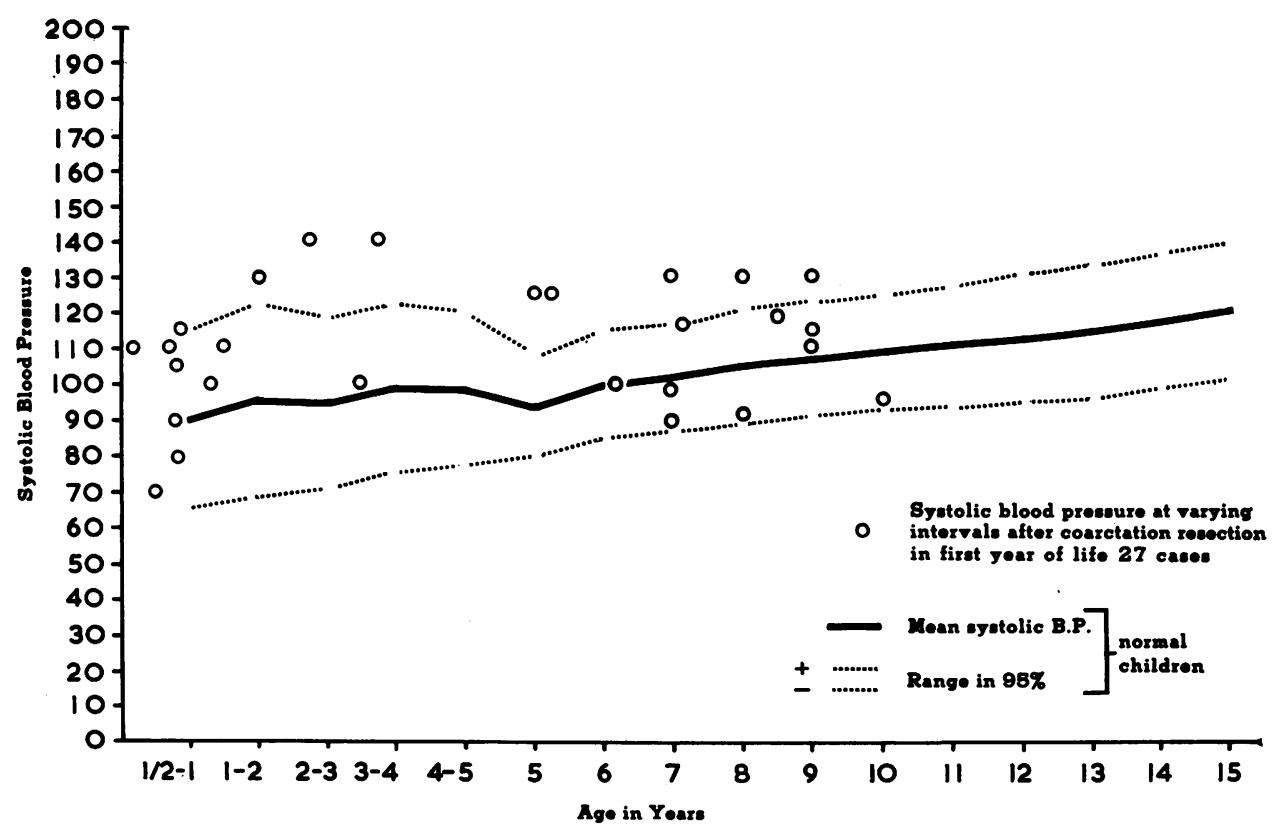

FIG. 1.-Post-operative systolic blood pressure readings in a group of 27 infants (Group A) when coarctation was resected in the first year of life. Blood pressure readings at various intervals after corrective surgery.

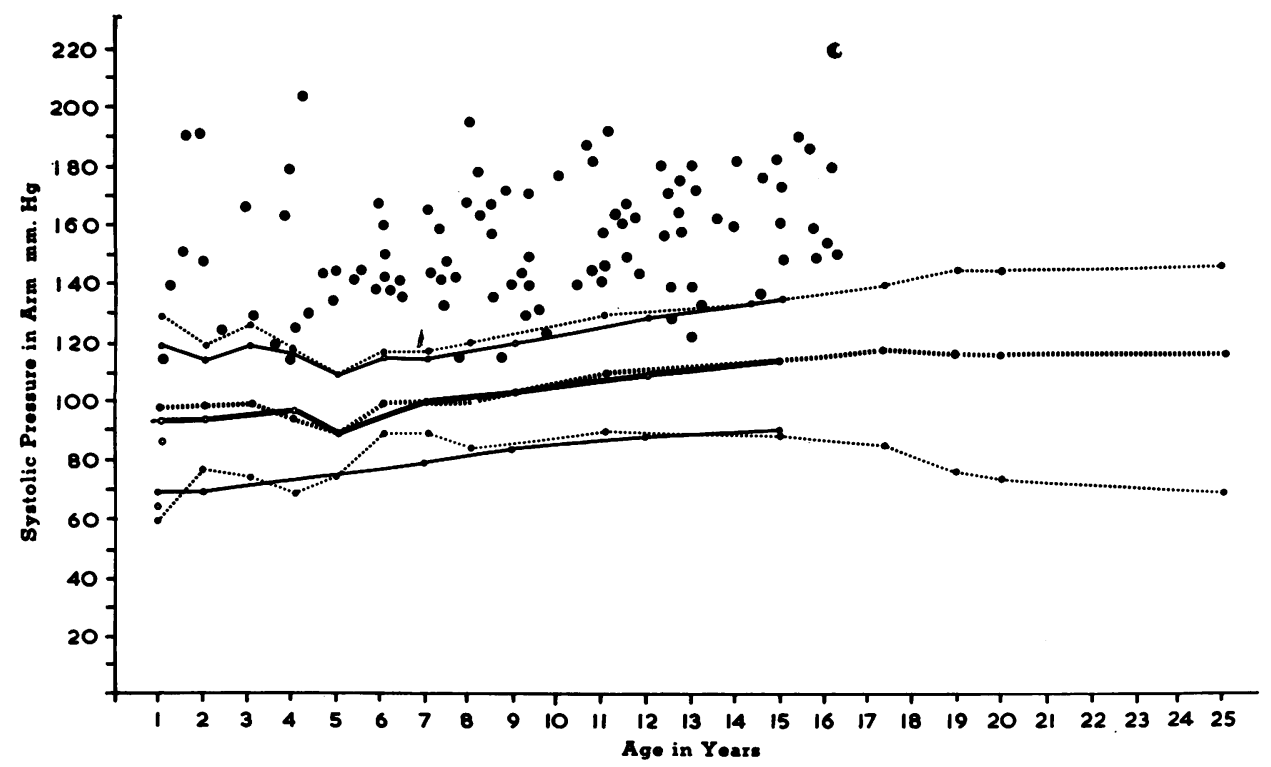

FIG. 2.-Systolic arm pressures before operation in 123 children (Group B), whose coarctation was resected after 1 year, are plotted against age. The mean and \pm S.D. lines represent values from normal population as described in the text. 


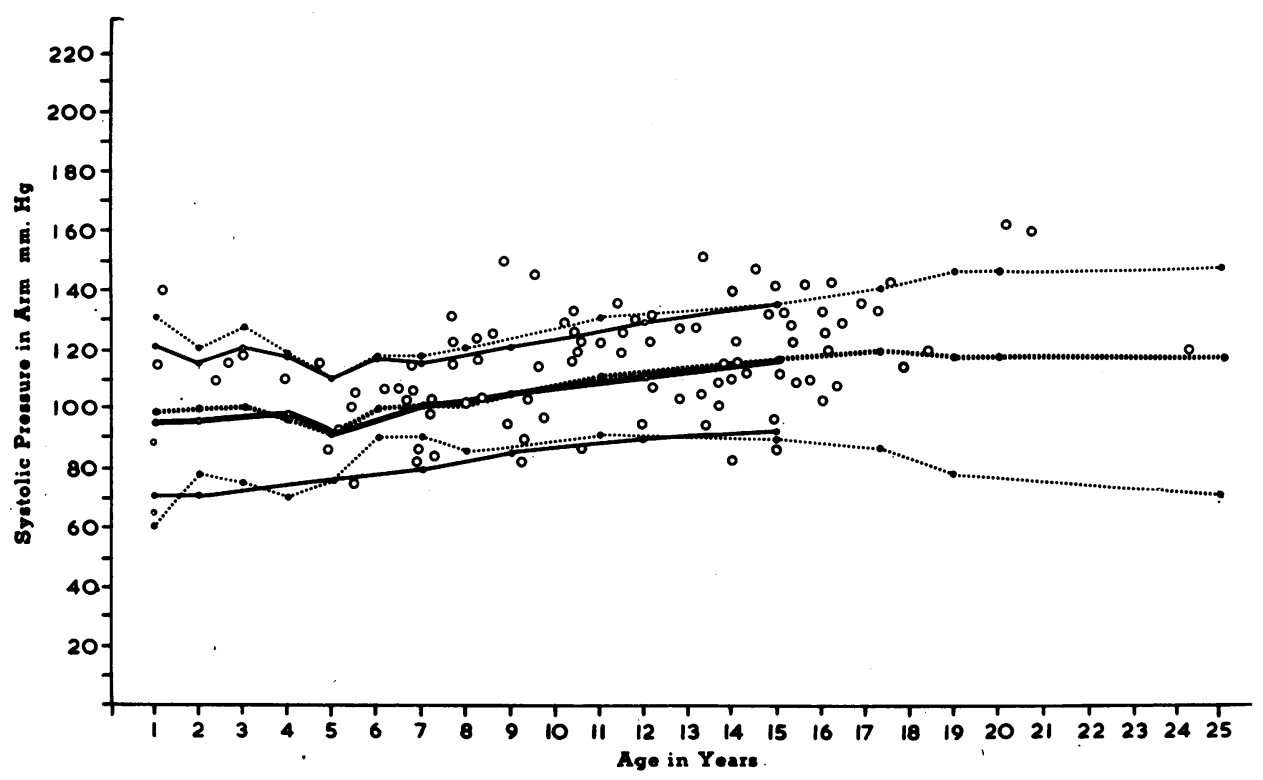

FIG. 3.-Post-operative systolic pressures in the arms, at the last follow-up, in 95 patients from Group $\mathrm{B}$, are plotted against age in the same way as in Fig. 2. 80 per cent of patients have pressures within the normal limits.

intracardiac defects. All patients with the exception of one had good femoral pulses: this particular infant had a long hypoplastic segment of the aorta which could not be adequately corrected and the femoral pulsations continued to be weak.

Group B Infants. Pre-operative pressures were well above normal in 94 per cent of children and at the upper limits of normal in the rest (Fig. 2). Of the 65 patients whose blood pressures were recorded in the immediate post-operative period, 43 per cent had systolic pressure increased above the pre-operative level, 12 per cent had no change, and 45 per cent showed a decrease.

In the first post-operative week 19 per cent of patients had a moderate to marked rise in blood pressure and 16 per cent complained of abdominal pain.

Of the 105 patients whose blood pressure was recorded at the time of discharge from hospital, 14 per cent had pressures higher than before operation, 7 per cent had no change, and 79 per cent had a fall in systolic pressure of varying degrees. In this last group, 37 per cent had a fall in systolic pressure of less than $20 \mathrm{~mm}$., 33 per cent of between 21 to $50 \mathrm{~mm}$., and 11 per cent of over $50 \mathrm{~mm}$. Hg.

Blood pressures were recorded in arms and legs of 95 children at the last follow-up, an average of 4.4 years later. Of these 80 per cent had normal pressures in the right arm (Fig. 3 ) and 20 per cent had readings above the normal levels for their age. Comparison of arm and leg pressures revealed that 78 per cent of the children had higher pressures in the legs than in the arms, 10 per cent had equal pressures in arms and legs, and in the remaining children the pressures in the arm were higher. In all this group the femorals had a brisk pulsation.

On reviewing the data for each case separately there was no evidence of a progressive rise in pressure in the arm nor were there signs of progressive hypertension in the leg. The age at operation is shown in Fig. 4, the peak being at 9 and 10 years. 


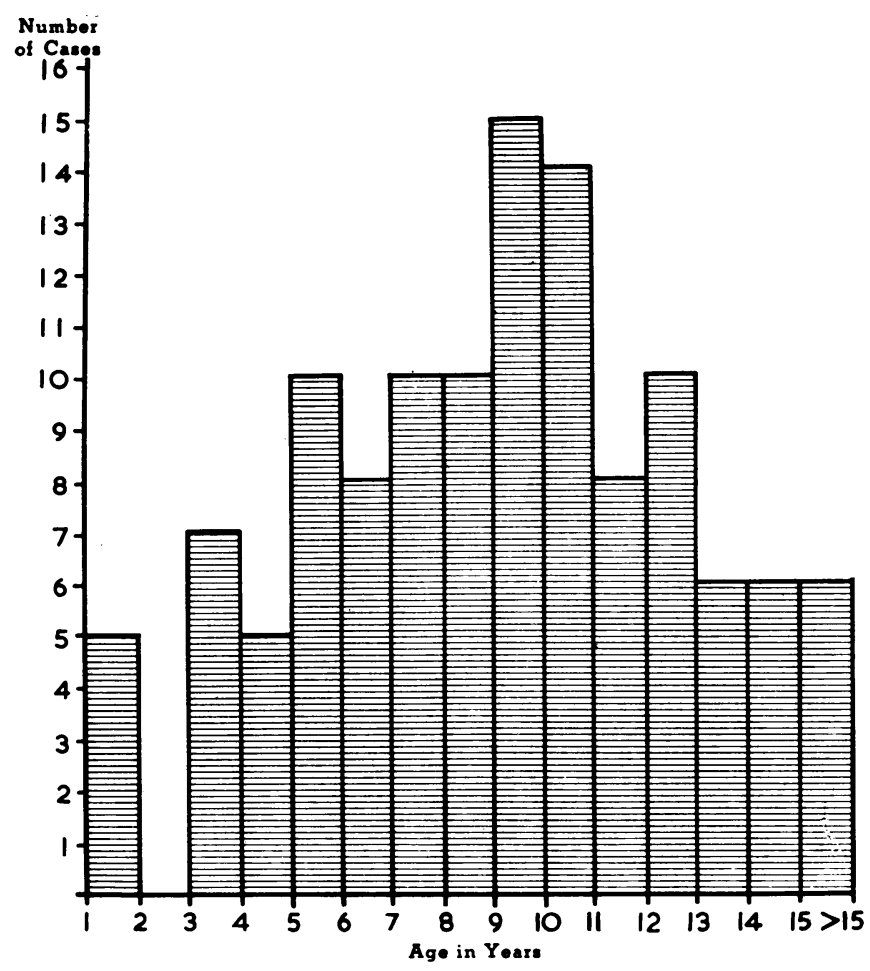

FIG. 4.-Age distribution of 123 patients in Group B at the time of operation. Distribution is fairly even with the peak between 9 and 11 years.

\section{Discussion}

Blood pressure is very labile for the first few days following repair of coarctation (Gross and Hufnagel, 1945; Keith et al., 1958). Immediately after the resection of the coarcted area blood pressure falls in the upper extremities, but after a few hours approximately one-fifth of the patients develop hypertension of some degree. This delayed rise is thought to be due to a reaction of the arterial bed below the coarctation caused by sudden increase in pressure when the obstruction is removed (Sealy et al., 1957). This effect seems to subside over the period of the next few days as a rule. The majority of the patients with paradoxical hypertension develop abdominal symptoms during the first post-operative weeks, but in general this is a non-surgical problem, though cases of massive infarction of the small bowel needing surgical resection have been reported (Gammelgaard and Friis-Hansen, 1960). None of the cases in our series required resection, though abdominal symptoms were considered severe enough in one patient for an exploratory laparotomy to be done: at operation moderate hyperæmia of the bowel was found but this patient, as did all others, made an excellent recovery. Blood pressure findings in a child developing paradoxical hypertension and abdominal pain after operation are described in Fig. 5.

There are relatively few reported series of long post-operative follow-up of patients operated on for coarctation of aorta under the age of 15 years. The Committee on Cardiovascular Disease, of the American College of Chest Physicians, recorded 1601 cases (Bailey, 1957). Only 22.9 per cent of the cases in this report were under the age of 15 years at the time of operation. Normal blood pressure was considered to be present shortly after operation in 72 per cent of the 1230 cases. However, figures were not given and the period of follow-up was not mentioned. 
Schuster and Gross (1962) reported the follow-up of 318 patients operated on for coarctation of aorta. The number of patients under the age of 15 years at the time of operation was not mentioned. At the last follow-up only 4 per cent of these had systolic pressures in the arms above $150 \mathrm{~mm}$. $\mathrm{Hg}, 36$ per cent had values between 130 and 150, and 60 per cent had pressures below 130 . However, these values were not compared with the normals for the age. We analysed systolic pressures in our patients in the same way and compared them with those of Schuster and Gross. Only 2.5 per cent of our patients had systolic pressures in the right arm over $151 \mathrm{~mm}$. Hg, 14.2 per cent had pressures between 131 and 150 , and 83.3 per cent had readings below 130 . It appears that our lower pressure levels are related to the lower average age at operation.

In their excellent report, March, Hultgren, and Gerbode (1960) compared the follow-up pressures of 38 patients operated on for coarctation with the expected values for the age. For normal values they used the compiled data of Nadas (1957) for infants and children, and the standards compiled by Master, Dublin, and Marks (1950) for the age-group over 16 years. Patients with blood pressures of more than two standard deviations from the mean value for the age were considered to be hypertensive. Their patients were followed from 1 to 9 years with the mean of 3.9 years. In this group, only 33 per cent were considered to have normal pressures at the time of discharge. At the last follow-up 24 per cent still had higher pressures, and 74 per cent had pressures within normal limits for the age. Using the same criteria 22 per cent of the patients in our series still had hypertension and 78 per cent had normal pressures.

Campbell and Baylis (1956) followed 30 patients from 1 to 7 years after repair of coarctation. In their group the average systolic pressure of all patients was $178 \mathrm{~mm}$. $\mathrm{Hg}$ before operation, and 137 $\mathrm{mm}$. Hg (ranging from 117 to 148) after operation. Cleland et al. (1956) followed 40 patients from 3 months to 8 years after resection of coarctation. More than 25 patients were over the age of 15 years at the time of operation, and 20 were studied in detail (Counihan, 1956). At the last follow-up most of them had systolic pressures in the arm above normal limits for the age. d'Abreu and Parsons (1956) reported follow-up of 8 children operated on for coarctation of aorta under the age of 14

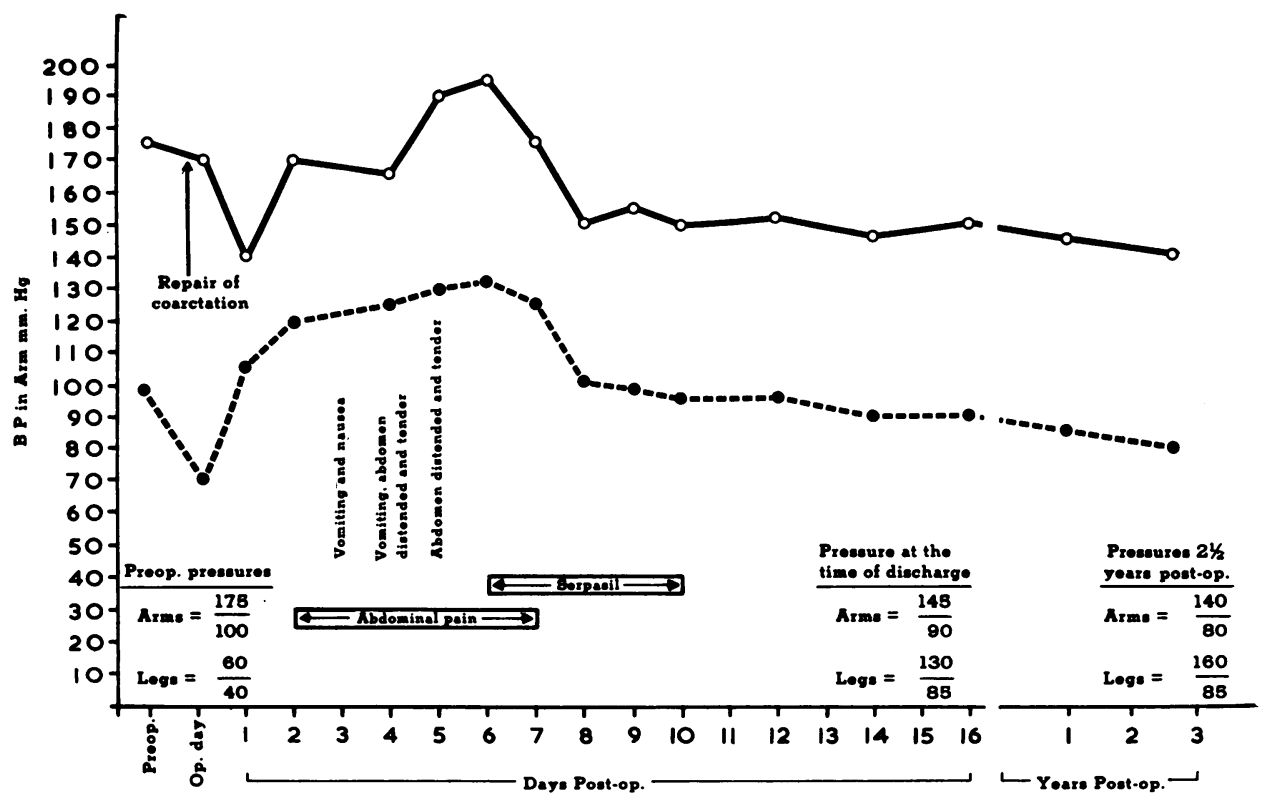

FIG. 5.-Post-operative course in an $8 \frac{1}{2}$-year-old boy (J.P.). Note that the pressures came down to near normal level immediately after operation and after about 48 hours he had a secondary rise in blood pressure associated with acute abdominal symptoms. Blood pressure was extremely labile during this period. 
years. Most of these had normal pressures at the last follow-up. The authors noted that after resection of coarctation blood pressures continued to fall for some weeks.

Most of the series mentioned above deal with patients who were mainly beyond the pædiatric age-group at the time of operation. In the present series all patients were under the age of 15 years at the time of operation. Of the total, 18 per cent (Group A) were under the age of 1 year, and 82 per cent (Group B) were between 1 and 15 years. Age distribution of patients in Group B was fairly even at the time of operation (Fig. 5). Follow-up pressures in Group A were compared with the normal values referred to previously (Keefer, Glenn, and Dotter, 1951). Systolic pressures within two standard deviations from the mean for the age were considered to be normal. In Group B, arm pressures were compared with the same standards used in Group A, and also with the normal values used by March et al. (1960). As already mentioned, 78 per cent of the total of the two groups had normal pressures in the arm. When analysed separately, the two groups revealed some differences. Among children of Group B, 80 per cent had normal pressures as against 67 per cent of infant Group A. However, only two patients in Group A had pressures over $140 \mathrm{~mm}$. Hg. All except one patient in Group A (followed for more than five years) had systolic pressures in the arms under $120 \mathrm{~mm}$. $\mathrm{Hg}$, though many of them had higher pressures when seen a few months after operation. The blood pressures did not show any tendency to rise after several years in the infant group; rather the reverse was noted. One patient with persistently high pressures after a long follow-up had a long hypoplastic coarcted segment at the time of operation and a normal aortic calibre could not be achieved.

There are many experimental studies on growth at the site of an aortic anastomosis in pigs and puppies, with conflicting data (Clatworthy et al., 1950; Groves and Effler, 1960; Hurwitt and Brahms, 1951; Nadas, 1957). Gaertner and Blalock (1956) and Schenk, Menno, and Martin (1961) studied the hæmodynamics of the experimentally created coarctation of varying degrees of severity in dogs. They found that the cardiac output was normal or high despite the marked constriction, and that flow through the constricted area remained at a relatively high level, in spite of a 94 per cent reduction in the cross-sectional area of the descending aorta.

Recently Bull et al. (1963) reported an experimental study of growth at the anastomotic site in the aorta. After performing aortic anastomoses at 5 to 8 weeks of age, they followed 19 puppies for periods of 9 to 13 months. (This is comparable to creating an anatomosis in a 4-year-old child's aorta and following him to maturity (Bull et al., 1963).) In their series all the patent anastomoses grew except two in which continuous sutures were used. In 10 out of 19 cases growth was comparable to the rest of the aorta. The average increase in vessel diameter during the observation period was 57 per cent, and of the anastomoses 52 per cent. The authors concluded that the growth of the vascular anastomosis will keep pace with that of the non-resected portion of the vessel, if the interrupted suture technique is used, and if the sutures are placed with skill to avoid initial constriction.

Moss et al.(1959) studied the growth of the anastomotic site in 5 infants approximately two to four years after operation, which had been carried out in the first year of life. They also made measurements of the aortas at necropsy of 154 subjects aged from 2 days to 74 years of age, in order to establish the rate of growth of that vessel. Their studies demonstrate that the diameter of the aorta at the level of the diaphragm increases about threefold during maturation. At 3 years of age it is about 55 per cent that of an adult. In the subjects studied after operation, some anatomical narrowing of aorta occurred in four, but no physiological obstruction could be demonstrated. Since physiological obstruction was not apparent with an aortic diameter of 55 per cent of the expected normal, and since the average diameter in children of 3 years of age is about 55 per cent that of an adult, the authors concluded that anastomosis performed at this age should remain functionally patent regardless of the future growth, and that, even if an operation was performed at 1 month of age, retardation of growth would have to exceed 65 per cent to result in a physiologically significant obstruction.

\section{CONCLUSION}

There are several earlier post-operative blood pressure studies on coarctation of the aorta extending over several years. The majority of them are in the age-group 10 to 40 years. These studies 
have shown that after four or more years 75 per cent have residual blood pressures within the upper limits of normal. In the present study the infants operated upon in the first year of life, when followed for several years, have blood pressure readings that are as close to normal range as in other reported studies in children over 1 year at the time of operation.

The factors that militate against an adequate fall in blood pressure after repair of the coarctation are:(1) continuous suture technique (Mustard et al., 1955); (2) prolonged area of hypoplastic coarcted segment; (3) older age-group with atherosclerotic changes in the central and peripheral arteries; (4) other causes of systemic hypertension unrelated to coarctation; and (5) in patients, particularly infants, operated upon in moribund condition as a life-saving procedure, making adequate resection and surgical repair technically difficult (Morris et al., 1960; Sauvage and Harkins, 1952).

The optimum age for surgical correction of coarctation, as recommended by Mustard et al. (1955), appears to be between 3 and 6 years of age; but if operation is required earlier, satisfactory results can be obtained with modern techniques. No patient should be denied the benefit of operation because of early age, if operation is required as a life-saving measure. It is now well recognized that congestive heart failure in the first two months of life in an infant with coarctation of aorta carries with it a very high mortality. The mortality is lower in this age-group when the coarctation has been resected.

\section{SUMMARY}

Post-operative blood pressures were studied in 150 patients from 6 months to 11 years following resection of coarctation of aorta. All of them were under 15 years at the time of operation. Twentyseven patients were under the age of 1 year at operation and 123 were between 1 and 15 years.

Changes in blood pressures in the immediate and late operative period were analysed. The majority of the patients, irrespective of their age at the time of operation, had normal blood pressures in the arms at the last examination.

Experimental and clinical evidence from earlier reports and from our own data, suggests that there is usually an adequate growth of the anastomotic site in the aorta even if operation is performed during infancy, and satisfactory results can be obtained with present techniques. In a minority of patients the blood pressure in the arm has remained slightly above the limits of normal, but there has been no progressive rise in blood pressure above the resected site and no evidence indicative of the development of obstruction or restenosis from lack of localized arterial growth.

\section{REFERENCES}

Bailey, C. P. (1957). Report of the section on cardiovascular surgery, American College of Chest Physicians. Surgical treatment of coarctation of the aorta. Dis. Chest, 31, 468.

Bull, C., Hoeksema, T., Duckworth, J. A., and Mustard, W. T. (1963). An experimental study of the growth of arterial anastomoses. Canad. J. Surg., 6, 383.

Campbell, M., and Baylis, J. H. (1956). The course and prognosis of coarctation of the aorta. Brit. Heart J., 18,475 .

Clatworthy, H. W., Sako, Y., Chisholm, T. C., Culmer, C., and Varco, R. L. (1950). Thoracic aortic coartation. Surgery, 28, 245.

Cleland, W. P., Counihan, T. B., Goodwin, J. F., and Steiner, R. E. (1956). Coarctation of the aorta. Brit. med. J., $2,379$.

Counihan, T. B. (1956). Changes in the blood pressure following resection of coarctation of the aortic arch. Clin. Sci., 15, 149.

Crafoord, C., and Nylin, G. (1945). Congenital coarctation of the aorta and its surgical treatment. J. thorac. Surg., 14, 347.

d'Abreu, A. L., and Parsons, C. (1956). Surgical treatment of children with coarctation of the aorta. Brit. med. J., 2, 390.

Gaertner, R. A., and Blalock, A. (1956). Experimental coarctation of the ascending aorta. Surgery, 40, 712.

Gammelgaard, A., and Friis-Hansen, B. (1960). Acute abdominal reaction following operation for coarctation of the aorta. Acta chir. scand., 119, 361.

Glass, I. H., Mustard, W. T., and Keith, J. D. (1960). Coarctation of the aorta in infants. Pediatrics, $26,109$.

Gross, R. E., and Hufnagel, C. A. (1945). Coarctation of the aorta. Experimental studies regarding its surgical correction. New Engl. J. Med., 233, 287.

Groves, L. K., and Effler, D. B. (1960). Problems in the surgical management of coarctation of the aorta. J. thorac. cardiovasc. Surg., 39, 60. 
Hurwitt, E. S., and Brahms, S. A. (1951). Observations on the growth of aortic anastomoses in puppies. Ann. Surg., $133,200$.

Keefer, E. B. C., Glenn, F., and Dotter, C. T. (1951). Resection and end-to-end anastomosis of the thoracic aorta in puppies; two and three-quarter year follow-up. Ann. Surg., 134, 969.

Keith, J. D., Rowe, R. D., and Vlad, P. (1958). Heart Disease in Infancy and Childhood. Macmillan, New York.

March, H. W., Hultgren, H. N., and Gerbode, F. (1960). Immediate and remote effects of resection on the hypertension in coarctation of the aorta. Brit. Heart J., $22,361$.

Master, A. M., Dublin, L. I., and Marks, H. H. (1950). The normal blood pressure range and its clinical implications. J. Amer. med. Ass., 143, 1464.

Morris, G. C., Cooley, D. A., De Bakey, M. E., and Crawford, E. S. (1960). Coarctation of the aorta with particular emphasis upon improved techniques of surgical repair. J. thorac. Surg., 40, 705.

Moss, A. J., Adams, F. H., O'Loughlin, B. J., and Dixon, W. J. (1959). The growth of the normal aorta and of the anastomotic site in infants following surgical resection of coarctation of the aorta. Circulation, $19,338$.

Mustard, W. T., Rowe, R. D., Keith, J. D., and Sirek, A. (1955). Coarctation of the aorta with special reference to the first year of life. Ann. Surg., 141, 429.

Nadas, A. S. (1957). Pediatric Cardiology. Saunders, Philadelphia.

Sauvage, L. R., and Harkins, H. N. (1952). Growth of vascular anastomoses: an experimental study of the influence of the suture type and suture method with a note on certain mechanical factors involved. Bull. Johns Hopk. Hosp., 91, 276.

Schenk, W. G., Menno, A. D., and Martin, J. W. (1961). Hemodynamics of experimental coarctation of the aorta. Ann. Surg., 153, 163.

Schuster, S. R., and Gross, R. E. (1962). Surgery for coarctation of the aorta. A review of 500 cases. J. thorac. cardiovasc. Surg., 43, 54.

Sealy, W. C., Harris, J. S., Young, W. G., and Calloway, H. A. (1957). Paradoxical hypertension following resection of coarctation of aorta. Surgery, 42, 135. 